\author{
홀스타인 착유우의 착유시간, 착유속도 및 착유량에 대한 \\ 유전모수 추정 \\ 안병석* · 주종철** · 전병순* • 박성재* • 백광수* • 박수봉* \\ 농촌진흥청 축산연구소*, 천안연암대학**
}

\title{
Genetic Parameters for Milking Duration, Milk Flow and Milk Yield Per Milking in Holstein Dairy Cattle
}

\author{
B. S. Ahn*, J. C. Ju**, B. S. Jeon*, S. J. Park*, K. S. Baek* and S. B. Park* \\ National Livestock Research Institute, RDA*, Cheonan Yonam College**
}

\begin{abstract}
This study estimated characteristics and genetic parameters for milking traits in Holstein dairy cattle. Daily records (12,561) were available from a hundred fifty four lactating cows with sixty six sires at National Livestock Research Institute from November, 2005 to April, 2006. The cows were fed same rations, and were milked twice daily using milking parlour equipped with Alpro-system ${ }^{\circledR}$ to collect milking records automatically. The experimental cows have averaged 1.9 parities, 139.7 days in milk, and $13 \mathrm{~kg}$ milk yield per milking. Average milk flow was $64 \%$ of peak milk flow. Milking duration, peak milk flow, average milk flow, and milk yield per milking were $5.57 \pm 1.67$ minutes, $3.58 \pm 0.79 \mathrm{~kg} /$ minute, $2.28 \pm 0.51$ $\mathrm{kg} /$ minute, and $13.02 \pm 4.09 \mathrm{~kg}$, respectively. All traits in the morning milking were higher than those of in the evening milking, and were also increased with parity. Heritabilities for milking duration, peak and average milk flow, and milk yield per time were $0.49,0.700 .58$ and 0.36 , respectively. The genetic correlations of milking duration with peak milk flow, average milk flow, and milk yield per time were -0.48 , -0.54 , and 0.41 , respectively. The correlations of milk yield per milking with peak milk flow and average milk flow were 0.23 and 0.30 , respectively. In conclusion, milk flow was increased with milk yield; however milk flow was opposite relationship with milk duration. Further studies are not only necessary to warranty genetic parameters, but pre-installation of automatic recording system to collect daily milking record is also necessary.
\end{abstract}

(Key words : Milking duration, Milk flow, Milk yield per milking, Correlations)

$$
\text { I. 서 론 }
$$

젖소에서 중요한 경제 형질은 말 할 것도 없이 유량과 우유 성분이다. 그러나 최근 경향은 호 당 사육 규모가 증가하고 있고 아울러 착유관 리에 소요되는 시간도 증가됨에 따라 착유 작
업효율도 중요한 요소가 되고 있다. 따라서 착 유실의 작업효율에 영향을 미치는 비유지속시 간(착유시간), 비유속도 등과 같은 비유형질이 낙농가의 관심을 끌게 되었다. 특히 착유시간 (비유지속시간)은 착유실의 작업시간과 작업의 흐름 등에 영향을 미치고 유질에도 영향을 미

Corresponding author : Byeong Seog, Ahn, National Livestock Research Institute, Seongwhan-eup Cheonan-si Chungcheongnam-do, 330-801. Republic of Korea

Tel : 041-580-3392, E-mail : abs3382@rda.go.kr 
친다는 보고(Zwald 등, 2005)도 있으며 외국에 서는 종모우 평가에도 비유속도 등이 활용 되 고 있다 (Holstein Canada, 1996; Boettcher 등, 1998; Zwald 등, 2005). 그러나 이들 형질에 대 하여 국내에서 보고된 연구는 일부에 지나지 않는다. 그러나 농가 사육규모의 증가와 이에 따른 시설의 규모화 등을 감안할 때 언젠가는 이들 형질이 우리나라 종모우 선발에 포함하여 야 할 것이라고 생각한다. 하지만 이를 측정할 수 있는 착유시설이나 착유기의 구비가 선행되 어야 하는 어려움이 있는 것도 현실이다. 비유 형질에 대한 연구결과에 의하면 착유시간(비유 지속시간), 비유속도 등이 지나치게 빠르게 되 면 유두의 괄약근 약화로 세균 감염이 용이하 여 유방염에 잘 걸릴 수도 있다고 하였으며 (Boettcher 등, 1998) 반대로 지나치게 늦어지 면 작업의 효율이 지연되거나 착유기의 장시 간 가동 등의 원인이 되므로 비유속도는 적당 한 수준이 바람직하다고 하였다(Zwald 등, 2005). 따라서 농가소득과 직접적인 관계는 크 지 않지만 작업효율과 비용지출에 영향을 미 치는 비유특성을 분석하는 것은 우군관리에도 중요할 것으로 생각되며 공시된 착유우의 두 수가 비록 제한적이기는 하지만 비유지속시간, 최고비유속도, 평균비유속도, 착유당 평균유량 에 대한 유전적 특성을 분석하여 향후 관련 연구에 필요한 기초자료를 제공하고자 수행하 였다.

\section{․ 재료 및 방법}

\section{1. 공시축}

본 연구를 위하여 공시된 젖소는 농촌진흥청 축산연구소에서 사육된 착유우로서 2005년 11 월부터 2006년 4월까지 1일 2회 착유를 하는 우군의 비유형질의 특성을 분석하였다. 시험축 은 하나의 우군으로 동일한 사양조건에 의하여 관리된 착유우 154 두 (종모우 66두)로부터 기록 을 수집 이용하였다. 공시된 자료에 대한 평균 유기는 139.7 일, 평균산차는 1.9 산, 착유당 평균 유량은 $13 \mathrm{~kg}$ 을 나타내었다. 공시축에 대한 유 기를 30 일 단위로 구분하여 착유시간과 산차 별 자료의 빈도는 Table 1 에 제시하였다. 공시된 자 료에 의하면 분만 후 150 일 이전에 착유한 자료 가 많았으며 수집된 기록 수는 오후에 비하여 오전이 많았고 산차 별 기록 수도 2산차가 1,3 산차에 비하여 많았음을 나타내고 있다.

\section{2. 통계분석}

공시축에 대한 착유는 12 두 $\times 2$ 열의 헤링본 착유실에서 숙련된 착유자에 의하여 1 일 2 회 수행되었으며 유량, 최고 및 평균 착유속도는 알프로 시스템(ver 6.4) ${ }^{\circledR}$ 에 의하여 측정하였다. 수집된 자료 17,214 개 중에서 보다 정확한 추 정치를 위하여 비유지속시간(milking duration)과

Table 1. Frequencies of days in milk by milking time (a.m. and p.m.) and parity

\begin{tabular}{|c|c|c|c|c|c|c|c|c|c|c|c|c|c|}
\hline \multirow{2}{*}{ Source } & & \multicolumn{12}{|c|}{ Days in milk* } \\
\hline & & D1 & D2 & D3 & D4 & D5 & D6 & D7 & D8 & D9 & D10 & D11 & Tot \\
\hline Total & & 1,501 & 1,511 & 1,665 & 1,946 & 1,486 & 667 & 671 & 603 & 686 & 743 & 1,082 & 12,561 \\
\hline \multirow{2}{*}{ Milking time } & a.m. & 840 & 709 & 805 & 994 & 760 & 390 & 471 & 443 & 411 & 390 & 571 & 6,784 \\
\hline & p.m. & 661 & 802 & 860 & 952 & 726 & 277 & 200 & 160 & 275 & 353 & 511 & 5,777 \\
\hline \multirow{3}{*}{ Parity } & $1^{\mathrm{st}}$ & 559 & 425 & 296 & 352 & 425 & 196 & 336 & 359 & 302 & 259 & 432 & 3,941 \\
\hline & $2^{\text {nd }}$ & 662 & 638 & 831 & 871 & 563 & 198 & 68 & 129 & 258 & 387 & 543 & 5,148 \\
\hline & $\geq 3^{\text {rd }}$ & 280 & 448 & 538 & 723 & 498 & 273 & 267 & 115 & 126 & 97 & 107 & 3,472 \\
\hline
\end{tabular}

* D1: 6 30, D2: 31 60, D3: 61 90, D4: 91 120, D5: 121 150, D6: 151 180, D7: 181 210, D8: 211 240, D9: 241 270, D10: 271 305, D11: 306 365 days in milk. 
최고 및 평균비유속도는 $2 \times$ 표준편차의 범위에 있는 자료를, 착유당 유량(milk yield per milking) 은 일반적인 건유 수준인 최저 $5 \mathrm{~kg}$ 에서 최고 $25 \mathrm{~kg}$ 의 범위에 있는 자료를 분석에 이용하였다 (Table 1). 비유특성인 비유지속시간, 최고비유 속도, 평균비유속도 및 착유당 평균유량에 대 하여 착유시간(a.m./p.m.), 산차 및 비유기 효과 를 추정하였으며 이를 위하여 SAS 프로그램 (Ver. 9.1)을 이용하여 $y_{i j k l}=\mu+T_{i}+P_{j}+D_{k}+e_{i j k l}$ 와 같은 모형으로 분석하였다. 여기서 $\mu$ 는 전 체평균, $T$ 는 오전과 오후에 따른 착유시간의 고정효과 $(i=1,2), P$ 는 산차의 고정효과로서 3 산차 이상은 3 산차로 간주하였고 $(j=1, ., 3), \mathrm{D}$ 는 Table 1 에서와 같이 30 일 간격으로 구분하 여 고정효과로 간주하였고 $(k=1, . ., 11), e_{i j k l}$ 은 나 머지 임의효과로 간주하였다. 각 형질에 대한 분 산과 공분산은 Kovac과 Groeneveld (2003)이 제 시한 REML에 의한 VCE-5 프로그램을 이용하되 일일 유량은 비유곡선으로서 분석모형에 포함하 였다. 분석모형은 $y_{i j k}=\mu+A_{i}+l s(D I M)_{j}+e_{i j k}$ 와 같고 여기서 $\mu$ 는 전체평균, $A_{i}$ 는 $\left(0, A^{2}{ }_{a}\right)$ 의 분산을 가지는 임의의 개체효과, $\mathrm{A}$ 는 개체의 혈연계수행렬, $l s(D I M)_{j}$ 은 공변량으로 $\mathrm{Ali}$ 와 Schaeffer (1987)가 제시한 j검정일에 의한 회귀 함수로서 $y_{t}=a+b \gamma_{t}+c \gamma^{2}{ }_{t}+d W_{t}+e W^{2}{ }_{t}+e_{t}$ 이 다. $\gamma_{t}=t / 305, \mathrm{~W}_{\mathrm{t}}=\log (305 / t), a$ 는 최고유량을 나타내는 상수, $b$ 와 $c$ 는 최고유량 이후 감소를 나타내는 계수, $d$ 와 $e$ 는 최고유량까지 증가를 나타내는 계수, $t$ 는 착유일수, $e$ 는 임의오차로 간주하였으며 비유곡선의 회귀계수는 참고문헌 과 같고(Silvestre 등, 2006), $e_{i j k}$ 은 나머지 임의효 과로 간주하였다. 유전상관은 VCE-5를 이용하 였으며 표현형 상관은 SAS 프로그램을 이용하 여 추정하였다.

\section{III. 결과 및 고찰}

공시된 착유우의 일반적인 특성은 Table 2와 같다. 비유지속시간, 최고비유 속도, 평균비유 속도 및 유량 등은 앞선 보고와 비슷한 수준이 었다(안 등, 1996, 2005; Zwald 등, 2005). 비유 지속시간과 비유속도는 유방압력, 유두 괄약근, 유방에 남아있는 유량, 혈중 옥시토신, 착유기 압력 등과 같이 다양한 요인에 의하여 영향을 받지만 특히 혈중 옥시토신 농도는 자극 후 10 여분이 경과하면 자극 전 수준으로 환원됨을 감안하여 관리하는 것이 바람직하다고 하였다 (Schmidt 등, 1988). 또한 착유시 스트레스를 적 게 하는 것도 중요할 뿐 만 아니라(Bruckmaier 와 Blum, 1998), 지나친 착유시간(비유지속시 간)은 젖소의 유방관리에 중요한 요인이 될 수 있는데 이는 착유기의 압력이 유두에 손상을 주는 원인이 될 수 있을 뿐 만 아니라 착유가 완료된 다른 개체까지도 착유실에 대기하도록 하여 전체 착유시간에 영향을 미치는 경우도 발생하게 된다. 반면에 지나치게 비유지속시간 이 빠르면 유두의 괄약근의 수축 약화로 이어 져 유방염에 쉽게 노출될 수도 있으며 개체간 의 심한 차이는 작업 효율을 감소시킴으로 비 슷한 비유지속시간을 가지는 젖소를 선호한다 고 하였다(Dodd 와 Griffin. 1983; Zwald 등, 2005). 한편 평균 비유속도는 최고 비유속도의 $64 \%$ 수준으로 측정되었으며 이때 착유당 유량 은 $13 \mathrm{~kg}$ 정도이었다. 이는 안 등(1996)이 보고 한 비유지속시간 4.74 분, 최고비유속도 $3.83 \mathrm{~kg} /$ 분, 유량 $12.2 \mathrm{~kg}$ 과 비슷한 수준이었으며 최고 비유속도는 거의 비슷한 성적을 나타내었다. Van Reenen 등 (2002)도 비유 개시 후 2 130 일에 측정한 최고비유속도와 비유지속시간은

Table 2. General statistics for milking characteristics of experimental herd

\begin{tabular}{lccc}
\hline \multicolumn{1}{c}{ Source } & No. of record & Means \pm SD & CV (\%) \\
\hline \hline Milking duration, (min) & 12,561 & $5.57 \pm 1.67$ & 29.9 \\
Peak milk flow, (kg/min) & 12,561 & $3.58 \pm 0.79$ & 22.0 \\
Average milk flow, (kg/min) & 12,561 & $2.28 \pm 0.51$ & 22.3 \\
Milk yield per milking, (kg) & 12,561 & $13.02 \pm 4.09$ & 31.4 \\
\hline
\end{tabular}


$3.2 \sim 4.7 \mathrm{~kg} /$ 분과 $4.5 \sim 6.2$ 분이라고 하여 비슷한 결과를 보고하였다.

한편 이들 형질에 대하여 착유시간, 산차와 비유기에 따른 최소자승평균치는 Table 3에 제 시하였다. 비유지속시간, 최고비유속도, 평균비 유속도, 착유당 평균유량에 대하여 오후 착유 보다 오전 착유가 높게 나타났고, 산차간에서 는 비유지속시간을 제외하고 산차증가와 함께 증가하는 경향이었다. 이는 유량의 증가와 함 께 비유속도도 증가하는 것으로 미루어 볼 때 이들간의 정의 상관관계를 추정할 수 있을 것 이다. 비유지속시간과 유량은 분만 후 60 일 전 후에 나타나는 최고비유기 도달일수와 일치하 는 결과라고 생각된다. 따라서 본 연구에 대한 공시축이 비록 제한적인 두수이기는 하나 동일 우군에 대하여 매일 반복하여 비유 특성을 조 사한 자료라는 측면에서는 의미 있는 결과라고 생각되나 더 많은 두수에 대한 연구가 필요할
것으로 생각된다. 한편 최고 및 평균비유속도 는 상대적으로 조사기간에 걸쳐 증감을 반복하 는 변이를 보였는데 이에 대하여는 비유기간에 속해 있은 개체의 건강상태, 산차 효과 등과 같 은 요인에 의하여 영향을 받았을 것으로 사료되 며 추가적인 연구가 필요하다고 생각된다. Stewart 등 (2002)에 의하면 착유 당 평균유량이 $11 \mathrm{~kg}$ 인 경우에서 비유속도는 $2.21 \sim 2.39 \mathrm{~kg} /$ 분, 비유지속시간은 4.84 5.04분 정도라고 하였고, Zwald 등 (2005)에 의하면 비유지속시간은 1 13 분까지 분포하고 있으나 $4 \sim 5$ 분의 경우가 가 장 많았다고 하여 본 연구 결과와 비슷하였다. 한편 비유특성은 착유기간 동안에 다양한 요 인, 예컨대 환경과 유전적 요인에 의하여 변화 될 수 있기 때문에 한번으로 측정된 자료를 분석 하는 것은 미흡하다고 하였다 (Meyer와 Burnside, 1987).

한편, 비유지속시간, 최고 비유속도, 평균 비

Table 3. Least square means and standard error for milking character by parity and days in milk*

\begin{tabular}{lccccc}
\hline \multirow{2}{*}{ Source } & & $\begin{array}{c}\text { Milking duration } \\
(\mathrm{min})\end{array}$ & $\begin{array}{c}\text { Peak milk flow } \\
(\mathrm{kg} / \mathrm{min})\end{array}$ & $\begin{array}{c}\text { Average milk flow } \\
(\mathrm{kg} / \mathrm{min})\end{array}$ & $\begin{array}{c}\text { Milk yield } \\
(\mathrm{kg} / \mathrm{milking})\end{array}$ \\
\hline \hline \multirow{2}{*}{ Milking time } & a.m. & $5.84^{\mathrm{a}} \pm 0.01$ & $3.72^{\mathrm{a}} \pm 0.01$ & $2.38^{\mathrm{a}} \pm 0.01$ & $14.27^{\mathrm{a}} \pm 0.04$ \\
& p.m. & $4.76^{\mathrm{b}} \pm 0.02$ & $3.50^{\mathrm{b}} \pm 0.01$ & $2.18^{\mathrm{b}} \pm 0.01$ & $10.40^{\mathrm{b}} \pm 0.05$ \\
\hline \multirow{3}{*}{ Parity } & $1^{\text {st }}$ & $5.42^{\mathrm{a}} \pm 0.02$ & $3.18^{\mathrm{a}} \pm 0.01$ & $2.06^{\mathrm{a}} \pm 0.01$ & $11.81^{\mathrm{a} \pm 0.05}$ \\
& $2^{\text {nd }}$ & $5.10^{\mathrm{b}} \pm 0.02$ & $3.66^{\mathrm{b}} \pm 0.01$ & $2.32^{\mathrm{b}} \pm 0.01$ & $12.12^{\mathrm{b}} \pm 0.04$ \\
& $\geq 3^{\text {rd }}$ & $5.38^{\mathrm{a}} \pm 0.02$ & $3.99^{\mathrm{c}} \pm 0.01$ & $2.45^{\mathrm{c}} \pm 0.01$ & $13.07^{\mathrm{c}} \pm 0.05$ \\
\hline & $6 \sim 30$ & $5.97^{\mathrm{a}} \pm 0.03$ & $3.51^{\mathrm{a}} \pm 0.01$ & $2.22^{\mathrm{a}} \pm 0.01$ & $13.48^{\mathrm{a}} \pm 0.08$ \\
& $31 \sim 60$ & $6.43^{\mathrm{b}} \pm 0.03$ & $3.52^{\mathrm{a}} \pm 0.01$ & $2.32^{\mathrm{b}} \pm 0.01$ & $15.20^{\mathrm{b}} \pm 0.08$ \\
& $61 \sim 90$ & $6.21^{\mathrm{c}} \pm 0.03$ & $3.54^{\mathrm{a}} \pm 0.01$ & $2.32^{\mathrm{b}} \pm 0.01$ & $14.82^{\mathrm{c}} \pm 0.07$ \\
& $91 \sim 120$ & $5.92^{\mathrm{a}} \pm 0.03$ & $3.59^{\mathrm{b}} \pm 0.01$ & $2.27^{\mathrm{c}} \pm 0.01$ & $13.99^{\mathrm{d}} \pm 0.07$ \\
& $121 \sim 150$ & $5.29^{\mathrm{d}} \pm 0.03$ & $3.70^{\mathrm{c}} \pm 0.01$ & $2.31^{\mathrm{b}} \pm 0.01$ & $12.66^{\mathrm{e}} \pm 0.08$ \\
& $151 \sim 180$ & $4.81^{\mathrm{e}} \pm 0.05$ & $3.64^{\mathrm{b}} \pm 0.02$ & $2.22^{\mathrm{a}} \pm 0.01$ & $11.43^{\mathrm{f}} \pm 0.12$ \\
& $181 \sim 210$ & $4.79^{\mathrm{f}} \pm 0.05$ & $3.63^{\mathrm{b}} \pm 0.02$ & $2.26^{\mathrm{c}} \pm 0.01$ & $11.58^{\mathrm{f}} \pm 0.12$ \\
& $211 \sim 240$ & $4.58^{\mathrm{g}} \pm 0.06$ & $3.79^{\mathrm{c}} \pm 0.02$ & $2.34^{\mathrm{b}} \pm 0.01$ & $11.31^{\mathrm{f}} \pm 0.13$ \\
& $241 \sim 270$ & $4.57^{\mathrm{h}} \pm 0.05$ & $3.88^{\mathrm{d}} \pm 0.02$ & $2.41^{\mathrm{d}} \pm 0.01$ & $10.71^{\mathrm{g}} \pm 0.12$ \\
& $271 \sim 305$ & $4.72^{\mathrm{i}} \pm 0.05$ & $3.55^{\mathrm{ab}} \pm 0.02$ & $2.28^{\mathrm{bc}} \pm 0.01$ & $10.13^{\mathrm{h}} \pm 0.11$ \\
& $306 \sim 365$ & $5.03^{\mathrm{j}} \pm 0.04$ & $3.35^{\mathrm{e}} \pm 0.02$ & $2.11^{\mathrm{e}} \pm 0.01$ & $10.33^{\mathrm{h}} \pm 0.09$ \\
\hline
\end{tabular}

* LSM with different superscripts is different significantly. 
유속도 및 착유당 평균 유량에 대한 유전적 특 성은 Table 4에 제시하였다. 비유지속시간, 최 고비유속도, 평균비유속도 및 착유당 평균 유 량에 대한 유전력은 비교적 높게 추정되었다. 한편 비유지속시간과 최고 및 평균비유속도간 에는 부의 유전상관이, 비유지속시간과 착유당 유량간에는 정의 상관이, 최고비유속도가 평균 비유 속도와 착유당 유량에 대해서는 모두 정 의 상관을, 평균비유속도와 착유당 유량간에도 정의 유전상관을 보여 Table 3의 성적을 뒷받 침하였다. 비유지속시간에 대한 유전력(0.11 0.58)은 다양하다고 보고하였으며(Zwald 등, 2005; Boettcher 등, 1998; Lawstuen 등, 1988; 안 등, 1996), Ali와 Schaeffer (1987)가 비유곡선 함수 를 이용하여 추정한 유량(305일)에 대한 유전력 은 1 산차에서 $0.30,2$ 산차에서 0.36 이라고 하여 비슷한 수준이었다. 하지만 본 연구에서 추정 된 유전모수가 앞서 보고된 연구결과에 비하여 높은 경향을 보인 것은 제한된 두수(종모우 당 2 3두의 낭우)에 영향을 크게 받았다고 생각 될 뿐만 아니라 동일한 환경 등으로 인하여 오 차 분산이 적게 추정된 것으로 생각되며 향후 더 많은 두수를 이용한 연구가 필요하다고 생 각된다. 이상의 연구결과를 종합하면 유량이 증가하면 비유속도도 따라서 증가하는 결과를 보였고 비유지속시간은 비유속도에 영향을 받 는 것으로 나타났다. 그러나 보다 의미 있는 유전적 특성을 파악하기 위하여 더 많은 자료 를 이용한 연구가 필요할 것으로 생각되며 아 울러 이러한 비유 형질에 대하여 지속적으로 기록 저장할 수 있는 착유시설과 장비가 먼저 구비되어야 할 것으로 사료된다.
IV. 요 약

본 연구는 우군의 일일 유량에 대한 비유형 질의 특성을 분석하고자 하였으며 공시된 젖소 는 농촌진흥청 축산연구소에서 사육된 착유우 로서 2005년 11월부터 2006년 4월까지 1일 2회 착유를 하는 우군의 자료를 이용하였다. 시험 축은 하나의 우군으로 동일한 사양조건에 의하 여 관리된 종모우 66두를 가지는 착유우 154 두 에서 수집된 기록 12,561 개를 분석하였다. 공시 축의 평균유기는 139.7 일, 평균산차는 1.9 산, 착 유당 평균유량 $13 \mathrm{~kg}$ 을 나타내었다. 평균 비유 속도는 최고 비유속도의 $64 \%$ 수준으로 측정되 었다. 비유지속시간, 최고비유속도, 평균비유속 도, 착유당 평균유량에 대하여 오후 착유 보다 오전 착유가 높게 나타났고, 산차간에서는 비 유지속시간을 제외하고 산차증가와 함께 증가 하는 경향이었다. 비유지속시간, 최고비유속도, 평균비유속도 및 착유당 평균 유량에 대한 유 전력은 각 $0.49,0.70,0.58,0.36$ 으로 비교적 높 게 추정되었다. 한편 비유지속시간과 비유속도 간에는 부의 유전상관이, 비유지속시간과 착유 당 유량간에는 정의 상관이, 최고비유속도에 대한 평균비유 속도(0.87)와 착유당 유량(0.23) 은 정의 상관을 보였고, 평균비유속도와 착유 당 유량간(0.30)에도 정의 유전상관을 보였다. 결론적으로 비유속도는 유량과 함께 증가하였 으나 비유지속시간과는 부의 관계를 보였으나 보다 의미 있는 유전적 특성을 파악하기 위하 여 더 많은 두수를 이용한 연구가 필요할 것으 로 사료된다.

Table 4. Genetic parameters for milking characteristics of experimental herd

\begin{tabular}{lcccc}
\hline Traits & $\begin{array}{c}\text { Milking duration } \\
\text { ( } \mathrm{min})\end{array}$ & $\begin{array}{c}\text { Peak milk flow } \\
(\mathrm{kg} / \mathrm{min})\end{array}$ & $\begin{array}{c}\text { Average milk flow } \\
\text { (kg/min) }\end{array}$ & $\begin{array}{c}\text { Milk yield } \\
\text { (kg/milking) }\end{array}$ \\
\hline \hline Milking duration, (min) & $0.49 \pm 0.02$ & $-0.48 \pm 0.04$ & $-0.54 \pm 0.04$ & $0.41 \pm 0.05$ \\
Peak milk flow, (kg/min) & -0.24 & $0.70 \pm 0.01$ & $0.87 \pm 0.01$ & $0.23 \pm 0.05$ \\
Average milk flow, (kg/min) & -0.29 & 0.78 & $0.58 \pm 0.02$ & $0.30 \pm 0.05$ \\
Milk yield, (kg/milking) & 0.64 & 0.29 & 0.38 & $0.36 \pm 0.02$ \\
\hline
\end{tabular}

Heritabilities are on the diagonal, genetic correlations are on the above diagonal, phenotypic correlations are below diagonal. 


\section{V. 인 용 문 헌}

1. Ali, T. E. and Schaeffer, L. R. 1987. Accounting for covariances among test day milk yields in dairy cows. Can. J. Anim. Sci. 67:637-644.

2. Boettcher, P. J., Dekker, J. C. M. and Kolstad, B. W. 1998. Development of an udder health index for sire selection based on somatic cell scores, udder conformation, and milking speed. J. Dairy Sci. 81:1157-1168.

3. Bruckmaier, R. M. and Blum, J. W. 1998. Oxytocine release and milk removal in ruminants. J. Dairy Sci. 81:939-949.

4. Dodd, F. H. and Griffin, T. K. 1983. Machine milking. Technical bulletin 1. The National Institute for Research in dairying reading, England. The Hannah Research Institute, Ayr, Scotland. p194.

5. Holstein Canada. 1996. Who's who.

6. Kovac, M. and Groeneveld, E. 2003. VCE-5 User's Guide and Reference Manual Ver. 5.1.

7. Lawstuen, D. A., Hansen, L. B., Steuernagel, G. R. and Johnson, L. P. 1988. Management traits scored linearly by dairy producers. J. Dairy Sci. 71:788-799.

8. Meyer, K. and Burnside, E. B. 1987. Scope of subjective assessment of milking speed. J. Dairy Sci. 70:1061-1068.

9. SAS User's Guide: Statistics, Version 8.1 Edition. 1999. SAS Inst., Inc., Cary, NC.

10. Schmidt, G. H., Vleck, L. D. Van and Hutjens, M. F. 1988. Principles of dairy science. $2^{\text {nd }}$ ed. p59-65.
11. Silvestre, A. M., Petim-Batista, F. and Colaço, J. 2006. The accuracy of seven mathematical functions in modeling dairy cattle lactation curves based on test-day records from varying sample schemes. J. Dairy Sci. 89:1813-1821.

12. Stewart, S., Godden, S., Rapnicki, P., Reid, D., Johnson, A. and Eicker, S. 2002. Effects of Automatic Cluster Remover Settings on Average Milking, Duration, Milk Flow, and Milk Yield. J. Dairy Sci. 85:818-823.

13. Van Reenen, C. G., Van der Werf, J. T. N., Bruckmaier, R. M., Hopster, H., Engel, B., Noordhuizen, J. P. T. M. and Blokhuis, H. J. 2002. Individual Differences in Behavioral and Physiological Responsiveness of Primiparous Dairy Cows to Machine Milking. J. Dairy Sci. 85:25512561.

14. Zwald, N. R., Weigel, K. A., Chang, Y. M., Welper, R. D. and Clay, J. S. 2005. Genetic evaluation of dairy sires for milking duration using electronically recorded milking times of their daughters. J. Dairy Sci. 88:1192-1198.

15. 안병석, 최유림, 고문석, 김준식, 김경남, 김내수. 1996. 홀스타인 젖소의 관리 형질에 미치는 환경 효과와 모수 추정. 한국축산학회지. 38:337-340.

16. 안병석, 전병순, 백광수, 박성재, 이현준, 이왕식, 김상범, 박수봉, 김현섭, 주종철, 아즈말 칸. 2005. 착유우의 연속유량, 유량변이, 유성분, 체 세포수, 비유시간, 비유속도에 대한 산차, 착유시 간, 유기 및 착유간격의 효과. 한국동물자원과학 회지. 47:919-924.

(접수일자 : 2006. 6. 12. / 채택일자 : 2006. 8. 1.) 